\title{
Oreocharis jasminina (Gesneriaceae), a new species from mountain tops of Hainan Island, South China
}

\author{
Shao-Jun Ling, ${ }^{1,2}$, Shu-Ping Guan³, Fang Wen ${ }^{4}$, Yu-Min Shui ${ }^{5}$, Ming-Xun Ren'
}

I Center for Eco-Environmental Restoration Engineering of Hainan Province, College of Ecology and Environment, Hainan University, Haikou 570228, China 2 College of Life and Pharmaceutical Sciences, Hainan University, Haikou 570228, China 3 College of Horticulture, Hainan University, Haikou 570228, China 4 Gesneriad Conservation Centre of China, Guangxi Key Laboratory of Plant Conservation and Restoration Ecology in Karst Terrain, Guangxi Institute of Botany, Guangxi Zhuang Autonomous Region and Chinese Academy of Sciences, Guilin, Guangxi 541006, China 5 Key Laboratory for Plant Diversity and Biogeography of East Asia, Kunming Institute of Botany, Chinese Academy of Sciences, 650201 Yunnan, Kunming, China

Corresponding author: Ming-Xun Ren (renmx@hainanu.edu.cn); Yu-Min Shui (ymshui@mail.kib.ac.cn)

Academic editor: Eberhard Fischer | Received 18 January 2020 | Accepted 2 June 2020 | Published 26 August 2020

Citation: Ling S-J, Guan S-P, Wen F, Shui Y-M, Ren M-X (2020) Oreocharis jasminina (Gesneriaceae), a new species from mountain tops of Hainan Island, South China. In: Shui Y-M, Chen W-H, Ren M-X, Wen F, Hong X, Qiu Z-J, Wei Y-G, Kang M (Eds) Taxonomy of Gesneriaceae in China and Vietnam. PhytoKeys 157: 121-135. https://doi. org/10.3897/phytokeys.157.50246

\begin{abstract}
A new species of Gesneriaceae, Oreocharis jasminina S.J.Ling, F.Wen \& M.X. Ren from Hainan Island, south China, is highlighted and described. The new species is distinguished by its actinomorphic corolla, narrow floral tube and ovate anthers hidden in the floral tube. The new species also showed clear geographic and altitudinal isolation from the three currently-recognised Oreocharis species on the Island. Molecular phylogenetic analysis, based on nuclear ITS1/2 and plastid $\operatorname{trn} \mathrm{L}-\operatorname{trn} \mathrm{F}$ sequences, supported the delimitation of the new species, which forms a single lineage with all the other Oreocharis species from Hainan Island. The roles of geographic and floral isolation in the evolution of the new species and its affinities are discussed.
\end{abstract}

\section{Keywords}

Hainan Island, new taxon, Oreocharis

Copyright Shao-Jun Ling et al. This is an open access article distributed under the terms of the Creative Commons Attribution License (CC BY 4.0), which permits unrestricted use, distribution, and reproduction in any medium, provided the original author and source are credited. 


\section{Introduction}

The Oreocharis Bentham was recently re-circumscribed to a large genus by including ten more genera and over 135 species, based mainly on molecular phylogenetic studies (Möller et al. 2011, 2016; Xu et al. 2017; Möller 2019; Wen et al. 2019). The enlarged genus was predominantly distributed in China with some species in India, Myanmar, Thailand and Vietnam (e.g. Li and Wang 2005; Möller and Clark 2013; Möller et al. 2018). Regardless of the limited differences in habit and fruit structure, Oreocharis shows a strikingly-high diversity in floral syndromes (Li and Wang 2005; Wei 2010; Möller and Clark 2013).

As one of the globally-important biodiversity hotspots, Hainan Island harbours about 4000 seed-plant species, of which ca. 500 are endemics (Francisco-Ortega et al. 2010) and which are concentrated in the south-central mountains. Gesneriaceae, in Hainan Island especially, includes a high ratio of species endemism, eight out of the total of 24 species being endemic (Ling et al. 2017a). Currently, three taxa of Oreocharis are recorded on Hainan Island and all of them are Hainan-endemic and monophyletic, i.e. O. dasyantha Chun, O. dasyantha Chun var. ferruginosa Pan and O. flavida Merrill (Li and Wang 2005; Ling et al. 2020), while each of these species shows considerable variations in morphological traits (Wei 2010; Ling et al. 2020a).

During several fieldwork trips in the past three years, we found that some populations of Oreocharis on mountain tops in Hainan Island showed obvious differences in various morphological characters. After careful literature studies (Pan 1987; Li and Wang 2005; Wei 2010) and morphological and molecular examinations, we are convinced that populations from the mountain tops of Mt. Yingge and Mt. Limu represent a new species, which we report and describe here.

\section{Materials and methods}

\section{Morphological observations}

The field study and conservation on Gesneriaceae were undertaken by two of the authors (SJL and MXR) over a long period of time, especially focusing on the Hainan-endemic species (Ling et al. 2017a, b; Xing et al. 2018; Li et al. 2019). Morphological observations and measurements were carried out, based on living plants during fieldwork. All available specimens of Oreocharis species, stored in the herbaria in China (PE, KUN, IBK and IBSC), were examined. We also downloaded all Oreocharis specimens from JSTOR Global Plants (http://plants.jstor.org), and Chinese Virtual Herbarium (http://www.cvh.ac.cn) to compare detailed morphological traits between the proposed new species with the currently-accepted species of Oreocharis. Specifically, we compared morphological traits of the possible new species with all the three currently-recognised Oreocharis species from Hainan Island, i.e. $O$. dasyantha, $O$. dasyantha var. ferruginosa and $O$. flavida. The specimens of new species were collected over the past two years and deposited in the herbarium of Hainan University (HUTB) and Kunming Institute of Botany, Chinese Academy of Sciences (KUN). 


\section{Taxonomic sampling, DNA extraction and molecular markers}

The leaf samples of $O$. dasyantha, $O$. dasyantha var. ferruginosa, $O$. flavida and the putative new species were collected in the field and dried in a vascular bag with silica gel. Total genomic DNA extraction was conducted using CTAB methods (Doyle and Doyle 1987). One nuclear ribosomal DNA (nrDNA) sequence, the ITS region comprising spacer 1 , the $5.8 \mathrm{~S}$ gene and spacer 2 (White et al. 1990) and one chloroplast DNA (cpDNA) intron-spacer region $\operatorname{trnL}-\operatorname{trn} \mathrm{F}$ (Taberlet et al. 1991) were used in this study. Laboratory procedures followed Ling et al. (2020) and newly-acquired sequences were deposited in GenBank (Table 2).

\section{Alignments and phylogenetic analyses}

According to Möller et al. (2011), Chen et al. (2014) and Ling et al. (2020), Oreocharis sinohenryi (Chun) Mich.Möller \& A.Weber which had the closest phylogenetic relationships with the Hainan Oreocharis taxa was used as outgroup with sequences (Genbank with accession numbers HQ632913 and HQ633009). The original chromatograms from both directions of the ITS1/2 and $t r n \mathrm{~L}-\operatorname{trn} \mathrm{F}$ sequences were evaluated using Bioedit (Hall 1999) for base confirmation and contiguous sequences editing, then we manually aligned sequences, where necessary, using MEGA v.6.5 (Kumar et al. 2008) and ambiguous positions were excluded from the alignments. The ITS1/2 and trnL$\operatorname{trn} \mathrm{F}$ were concatenated to a single matrix after a congruency test by PAUP* 4.0a164 (Swofford 2003). Bayesian Inference (BI) analysis was conducted using MrBayes version 3.1.2 (Huelsenbeck and Ronquist 2001) and Maximum Likelihood (ML) analysis was performed using MEGA v.6.5 (Kumar et al. 2008). Both procedures followed the Ling et al. (2020), based on the combined ITS1/2 and $\operatorname{trn} \mathrm{L}-\operatorname{trn} \mathrm{F}$ sequences.

\section{Results}

\section{Phylogenetic reconstruction}

The combined ITS1/2 and $\operatorname{trn} \mathrm{L}-\operatorname{trn} \mathrm{F}$ datasets were 640 and 818 bp long, amongst which 64 and 17 were polymorphic sites and 27 and 6 were parsimony-informative sites, respectively. The aligned dataset was $1458 \mathrm{bp}$ long and a total number of 81 polymorphic sites were measured, of which 33 were parsimony-informative sites. There was no significant incongruence, based on the incongruence length difference (ILD) test between the ITS1/2 and $\operatorname{trn} \mathrm{L}-\operatorname{trnF}(\mathrm{p}>0.05)$.

Molecular phylogeny recognised the individuals from different mountains and these were grouped as separate lineages. The putative new species from Mt. Limu and Mt. Yingge is accepted as a new species with PP (posterior probability) $=1$ and BS (bootstrap value) $=100 \%$ (Fig. 1). All the Oreocharis species from Hainan Island form a single lineage with relatively-high support (Fig. 1). 


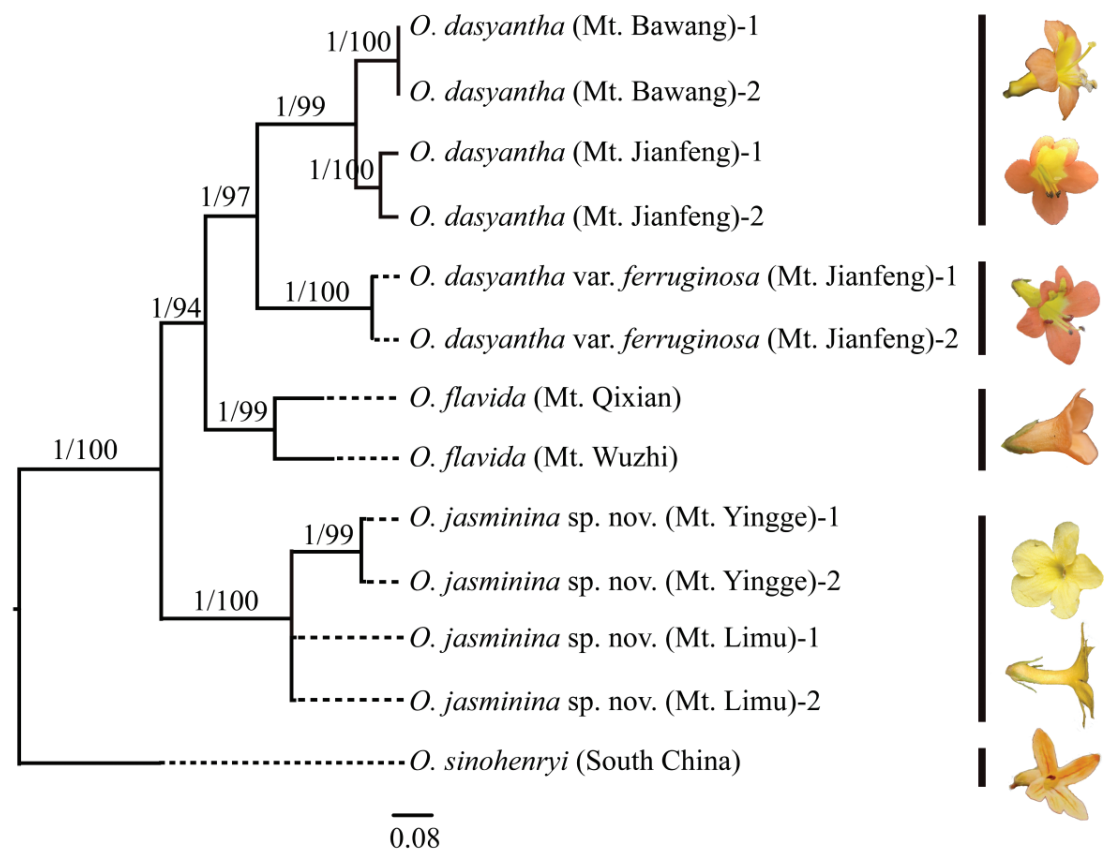

Figure I. Molecular phylogeny of Hainan Oreocharis taxa with outgroup O. sinohenryi, based on the combined nuclear ribosomal DNA (nrDNA) sequence ITS1/2 and chroloplast gene trnL-trnF data matrices. Posterior probability (PP) and Bootstrap value (BS) are showed above branches.

\section{Taxonomic treatment}

\section{Oreocharis jasminina S.J.Ling, F.Wen \& M.X. Ren, sp.nov.} urn:lsid:ipni.org:names:77211189-1

Figs 2, 3

Diagnosis. Oreocharis jasminina has the closest phylogenetic relationship with $O$. dasyantha, $O$. dasyantha var. ferruginosa and $O$. flavida with very high support values, all being Hainan-endemic and monophyletic. O. jasminina can be easily distinguished from them by having: (1) a long and narrow floral tube (both $O$. dasyantha and $O$. dasyantha var. ferruginosa have conical floral tubes, $O$. flavida has campanulate-tubular floral tube); (2) yellow and actinomorphic corolla (both $O$. dasyantha and $O$. dasyantha var. ferruginosa are zygomorphic with orange-red to yellow corolla, O. flavida is actinomorphic with orange corolla); (3) didynamous stamens with ovate anthers hidden in the floral tube (both $O$. dasyantha and $O$. dasyantha var. ferruginosa have exposed didynamous stamens with ovate anthers, $O$. flavida has four equivalent stamens with horseshoe-shaped anthers included in the floral tube) (Table 1, Fig. 4).

Type. China. Hainan: Qiongzhong County (琼中县), Limu Mountain, 1350 m a.s.l., on moist rocks, 26 Nov 2018, S.J.Ling 2018112601 (holotype: HUTB!; Isotypes: HUTB!, KUN!). 


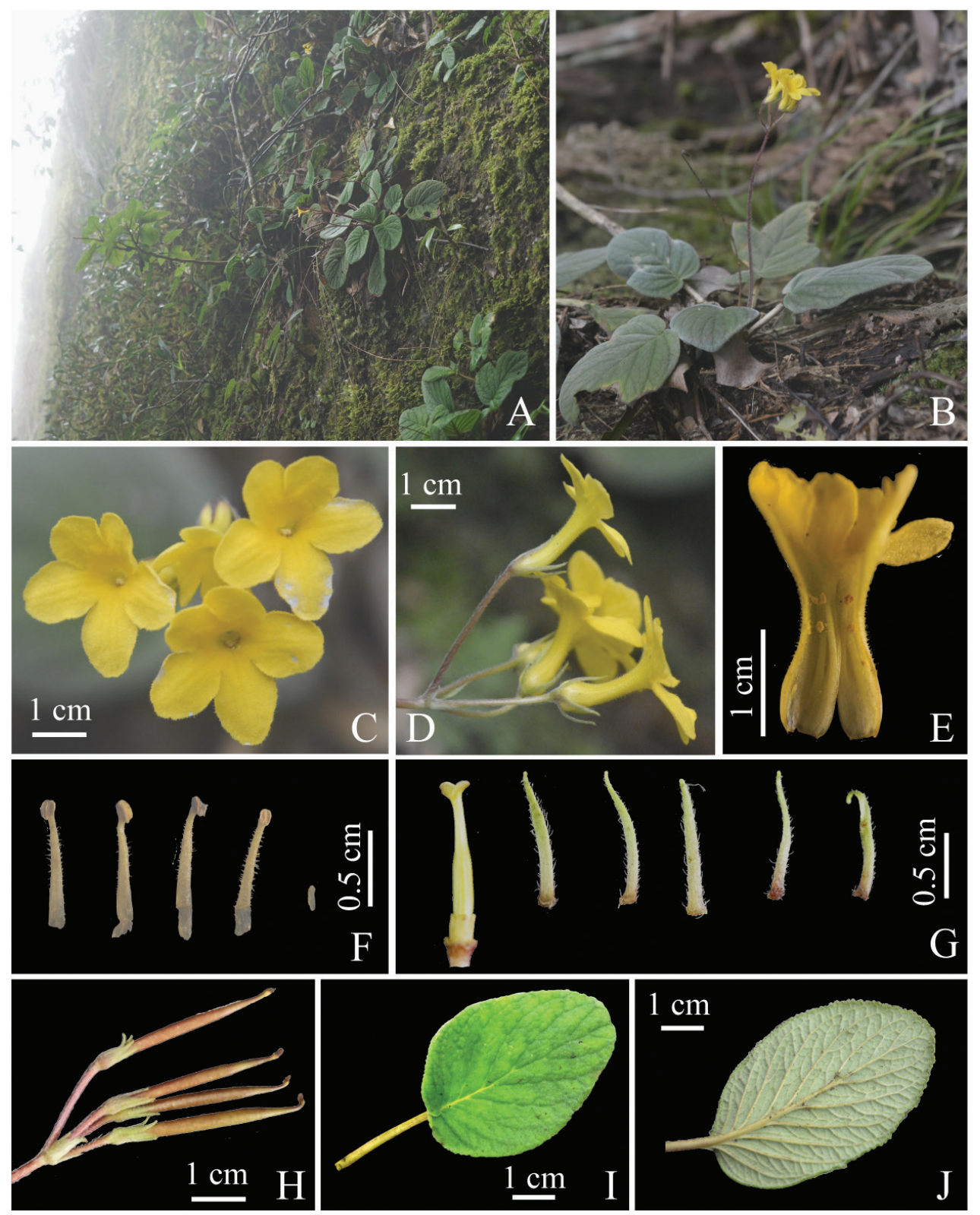

Figure 2. Oreocharis jasminina sp. nov. A Habitat $\mathbf{B}$ habit $\mathbf{C}$ face view of corolla $\mathbf{D}$ lateral view of corolla $\mathbf{E}$ opening flower showing stamens and staminode $\mathbf{F}$ stamens and staminode $\mathbf{G}$ pistil and sepals $\mathbf{H}$ fruit pods I adaxial leaf surface J abaxial leaf surface.

Description. Perennial herb, rhizomatous, leaves basal; $4.0-10.0 \mathrm{~cm}$ long, $2-3 \mathrm{~mm}$ in diameter, densely pale brown villous or woolly; leaf blade ovate to broadly ovate, rarely elliptic or obovate, $6-11 \times 4-8 \mathrm{~cm}$, adaxially densely grey to brown pubescent, abaxially sparsely to densely grey or grey-brown pubescent, sparsely brown villous along veins 


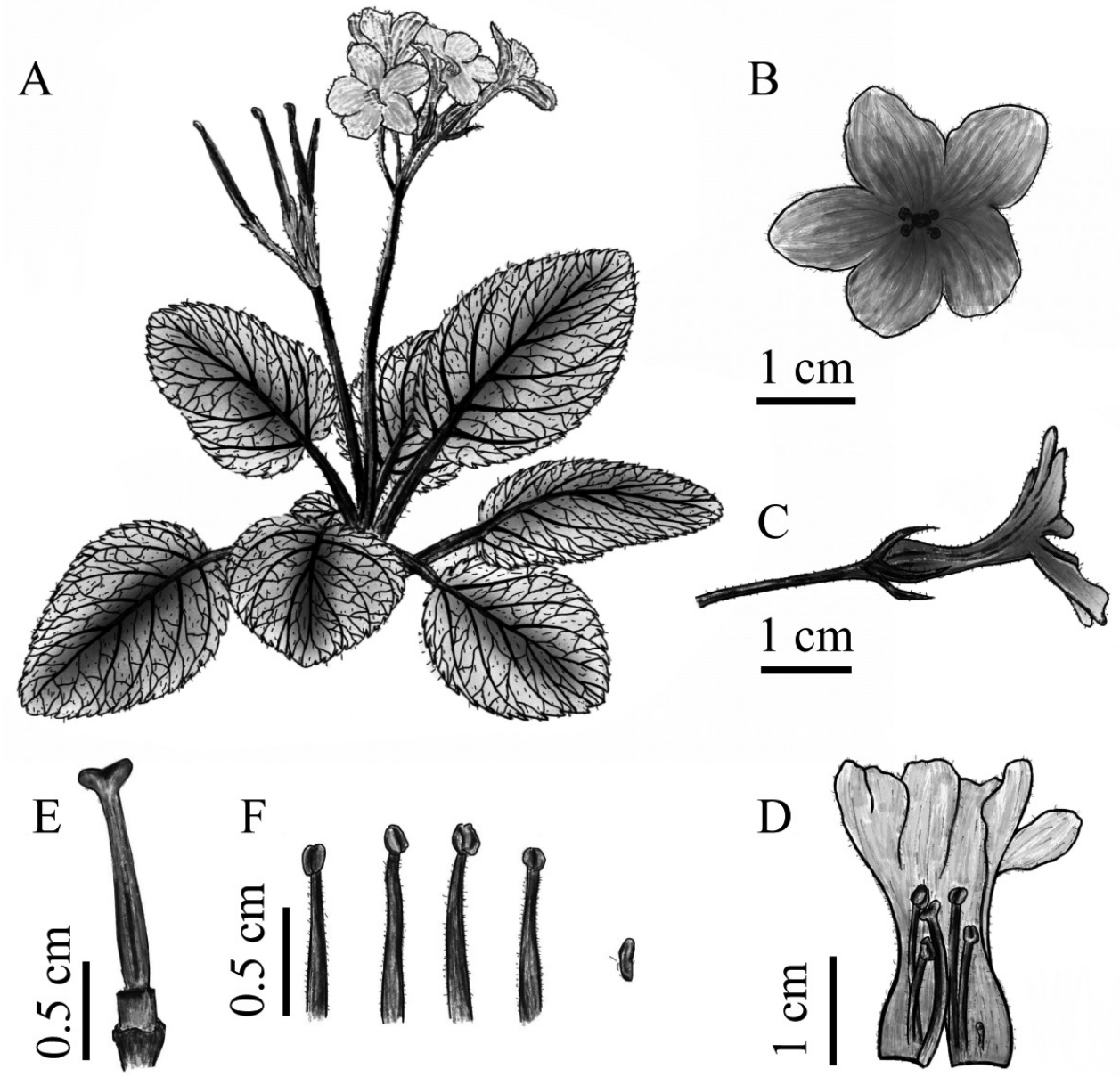

Figure 3. Oreocharis jasminina sp. nov. (all drawings based on the holotype S.J.Ling 20181126-01 in HUTB, drawn by S.P. Guan). A Habit B face view of corolla $\mathbf{C}$ lateral view of corolla $\mathbf{D}$ opening corolla showing pistil and stamens $\mathbf{E}$ pistil $\mathbf{F}$ stamens and staminode.

which are adaxially sunken and abaxially ridged, lateral veins 6-7 on each side of midrib, base often cordate to rounded, margin nearly entire to shallowly crenate, apex rounded. Cymes axillary, 2-3, inflorescence 3-10-flowered; Peduncle 9-16 cm long, sparsely pale grey villous; bracts 2 , linear to narrowly triangular, outside densely villous, apex acuminate, cuneate to triangular, margin entire; pedicel $1.5-2.2 \mathrm{~cm}$ long, densely pale brown villous to woolly. Calyx 5-lobed, divided to base, lobes green, narrowly lanceolate, 9-11 $\times$ ca. $2 \mathrm{~mm}$, apex acuminate, margin entire, outside villous, inside glabrous. Corolla yellow, 1.7-2.2 cm long, outside pubescent; tube thin tubular, $1.8-2.1 \mathrm{~cm} \times 3-4.5 \mathrm{~mm}$, limb barely 2-lipped, adaxial lip shallowly 2-lobed from near base, abaxial 3-lobed slightly equal. Stamens 4, 8-9 mm long, included, adnate to corolla 4-5 $\mathrm{mm}$ from base; filaments slender, pubescent; anthers ovate, 2-loculed, dehiscing transversely; staminode 1, adnate to corolla $2-4 \mathrm{~mm}$ from base, ca. $2 \mathrm{~mm}$. Disc ca. $1 \mathrm{~mm}$ high, entire. Pistil ca. 


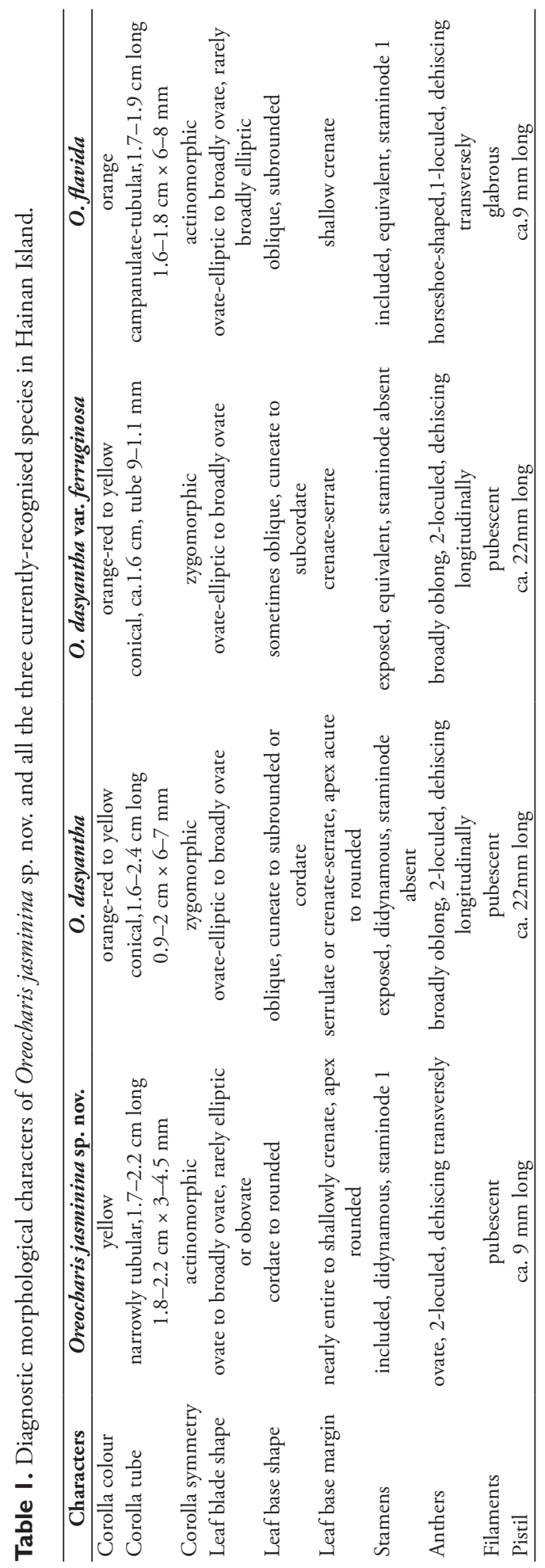




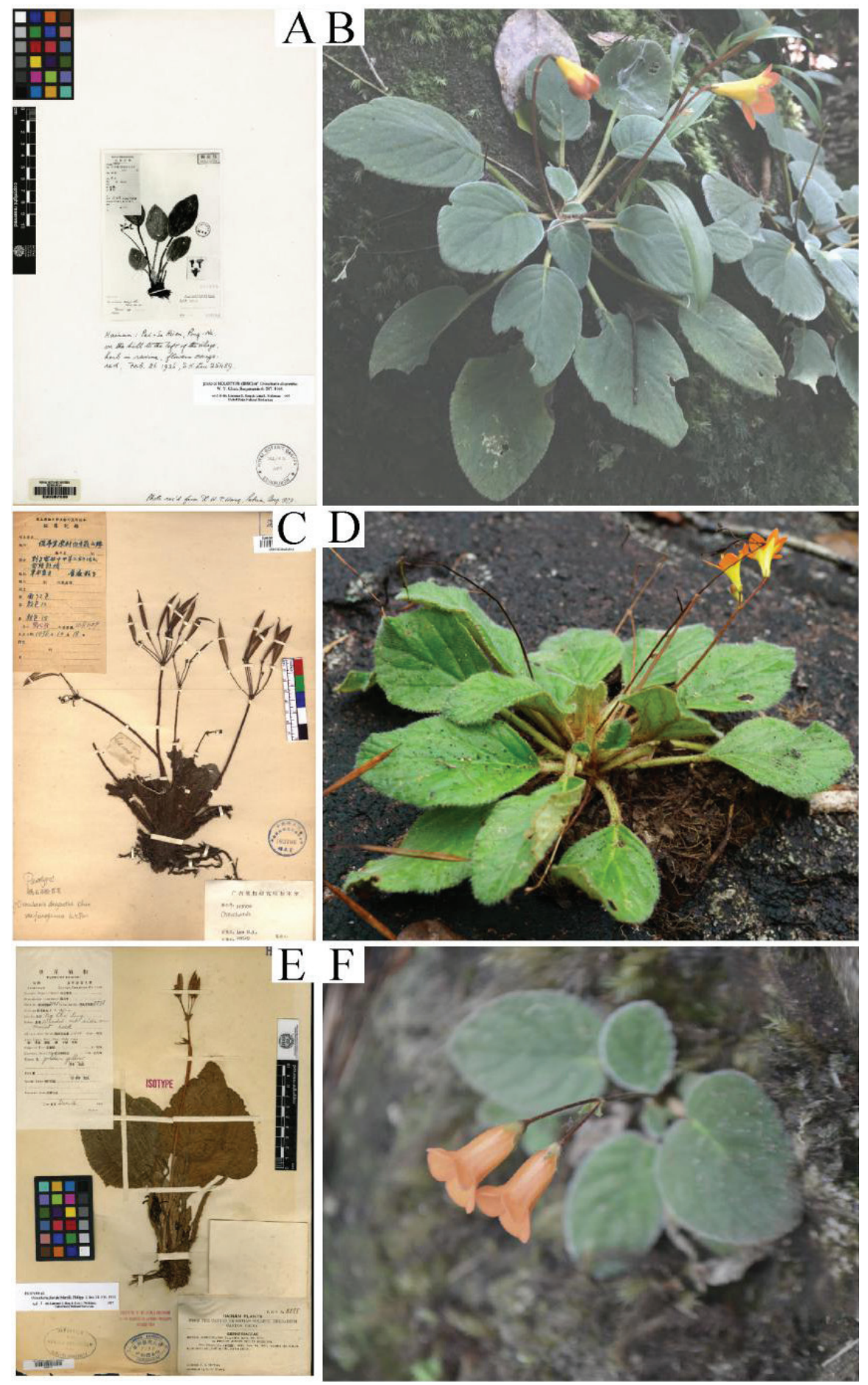

Figure 4. Three formerly-recognised Oreocharis taxa in Hainan Island. Oreocharis dasyantha $(\mathbf{A}, \mathbf{B})$, Oreocharis dasyantha var. ferruginosa $(\mathbf{C}, \mathbf{D})$ and Oreocharis flavida (E, F). 
Table 2. List of Hainan Oreocharis taxa and outgroup O. sinohenryi used in the phylogenetic analysis, including respective Genbank accession and voucher numbers.

\begin{tabular}{|c|c|c|c|}
\hline Species & $t r n \mathrm{~L}-t r n \mathrm{~F}$ & ITS1/2 & Voucher Number \\
\hline O. dasyantha Chun (Mt. Bawang)-1 & MK587993 & MK587954 & S.J.Ling \& M.X. Ren 2015011803 (HUTB) \\
\hline O. dasyantha Chun (Mt. Bawang)-2 & MK587994 & MK587954 & S.J.Ling \& M.X. Ren 2015011804 (HUTB) \\
\hline O. dasyantha Chun (Mt. Jianfeng)- 1 & MK587995 & MK587955 & S.J.Ling 2015102201 (HUTB) \\
\hline O. dasyantha Chun (Mt. Jianfeng)-2 & MK587996 & MK587955 & S.J.Ling 2015102202 (HUTB) \\
\hline $\begin{array}{l}\text { O. dasyantha Chun var. ferruginosa } \\
\text { Pan (Mt. Jianfeng)-1 }\end{array}$ & MK587954 & MK587956 & S.J.Ling 2015102203 (HUTB) \\
\hline $\begin{array}{l}\text { O. dasyantha Chun var. ferruginosa } \\
\text { Pan (Mt. Jianfeng)-2 }\end{array}$ & MK587954 & MK587957 & S.J.Ling 2015102204 (HUTB) \\
\hline O. flavida Merrill (Mt. Qixian) & MK587947 & MK587990 & S.J.Ling 2018112901 (HUTB) \\
\hline O. flavida Merrill (Mt. Wuzhi) & MK587989 & MK587943 & S.J.Ling 2018112902 (HUTB) \\
\hline O. jasminina (Mt. Yingge)-1 & MK587987 & MK587948 & S.J.Ling 2018112601 (HUTB) \\
\hline O. jasminina (Mt. Yingge)-2 & MK587988 & MK587950 & S.J.Ling 2018112602 (HUTB) \\
\hline O. jasminina (Mt. Limu)-1 & MK587981 & MK587949 & S.J.Ling 2018112603 (HUTB) \\
\hline O. jasminina (Mt. Limu)-2 & MK587982 & MK587953 & S.J.Ling 2018112604 (HUTB) \\
\hline $\begin{array}{l}\text { O. sinohenryi (Chun) Mich.Möller \& } \\
\text { A.Weber }\end{array}$ & HQ632913 & HQ633009 & M.Möller MMO 07-1150 (E) \\
\hline
\end{tabular}

$7 \mathrm{~mm}$ long; ovary cylindrical, ca. $5 \mathrm{~mm}$ long, glabrous. Stigma 2, equal, suborbicular. Capsula linear, 3-4 cm long, glabrous to sparsely puberulent.

Phenology. Oreocharis jasminina flowers from September to December and fruits from November to January.

Distribution and habitat. Oreocharis jasminina is currently only found in cloud forests on the mountain tops of Mt. Limu and Mt. Yingge, in the middle of Hainan Island. The habitat of $O$. jasminina is on the moss layer on wet rocks under cloud forests.

Etymology. The specific epithet refers to the yellow and narrowly tubular corolla of this new species.

Vernacular name. 迎春花马铃苣苔 (Yíng Chūn Huā Mă Líng Jù Tái) is the Chinese name for Oreocharis jasminina, the first three characters meaning 'winter jasmine', indicating its similar floral syndromes to Jasminum nudiflorum Lindl. The last four characters are the Chinese name for Oreocharis.

Conservation status. Oreocharis jasminina is, so far, known only from the two locations with about 800-1000 individuals. The populations are under threat due to the restricted and fragmented habitat. Therefore, we propose that $O$. jasminina should be considered as 'Vulnerable' (VU), according to the IUCN Red List Categories and Criteria (IUCN 2012).

Key to Oreocharis jasminina and its closely-related and sympatric species in Hainan Island

1 Anthers horseshoe-shaped, 1-loculed, dehiscing transversely O. flavida

- $\quad$ Anthers broadly oblong, 2-loculed, dehiscing longitudinally 
2 Stamens included, floral tube thin tubular, corolla yellow O. jasminina

- Stamens exposed, floral tube conical, corolla orange-red .............................. 3

3 Leaf blade adaxially grey pubescent, base oblique, subrounded to cordate, margin serrulate; petiole to $14.5 \mathrm{~cm}$, densely pale brown villous; cymes 1-3(or 4)-flowered; corolla $1.7-2.4 \mathrm{~cm}$, tube $1.1-2 \mathrm{~cm}$

O. dasyantha

- Leaf blade adaxially grey to brown pubescent and villous, base sometimes oblique, cuneate to subcordate, margin crenate-serrate; petiole to $6 \mathrm{~cm}$, densely pale brown woolly; cymes 3-8-flowered; corolla ca. $1.6 \mathrm{~cm}$, tube 9-11 mm

O. dasyantha var. ferruginosa

\section{Discussion}

Our former study showed the new species $O$. jasminina and the three other Hainanendemic taxa are homologous, indicating these species in Hainan Island had a common origin (Ling et al. 2020). The new species is only found on mountain tops higher than $1200 \mathrm{~m}$ in two mountains, Mt. Limu and Mt. Yingge, located at the middle of Hainan Island. These mountain tops likely formed island-like habitats because the deep and wide valleys interrupted gene flows, resulting in population differentiation and speciation (Shen et al. 2017; Ling et al. 2017a, b; Xing et al. 2018). Such 'sky islands' may be the main reason for the origin and maintenance of this Hainan-endemic alpine species (Robin et al. 2015; Ling et al. 2017a).

The new species also shows a clear geographic isolation from the three currently-recognised Oreocharis taxa on Hainan Island. The new species $O$. jasminina was only found in Mt. Limu and Mt. Yingge in the middle of the island, while $O$. dasyantha and $O$. dasyantha var. ferruginosa are restricted to the west side of the Island and $O$. flavida was only found in the east side (Fig. 5). They are isolated by a large river, the Changhua River (the second largest river on Hainan Island). Li et al. (2019) found that the geographic isolation by the Changhua River is a driving force for the great population differentiation in the two Hainan-endemic Gesneriaceae species, Primulina heterotricha (Merr.) Yan Liu and Metapetrocosmea peltata (Merr. et Chun) W. T. Wang. Thus, the geographic isolation by rivers or valleys may also play a key role in the evolution of O. jasminina and other Hainanendemic Oreocharis taxa. However, the relative contributions of such geographic isolation and altitudinal differentiation are still in need of further experimental examination.

Floral symmetry is widely recognised as a key trait in pollination and taxonomy. Normally, the zygomorphic corolla possesses higher pollen-transfer efficiency than the actinomorphic corolla (Sargent 2004). Oreocharis jasminina has yellow actinomorphic corolla with a long and narrow floral tube, differing from $O$. dasyantha and $O$. dasyantha var. ferruginosa (both have zygomorphic corolla). Although O. flavida has an actinomorphic flower, its campanulate corolla with four equivalent stamens and horseshoe-shaped anthers make it distinct from the new species $O$. jasminina (Table 1).

Floral shape was expected to be a vital factor in generating floral isolation and evolutionary shifts (Castellanos et al. 2004; Muchhala 2007). Generally, the floral 


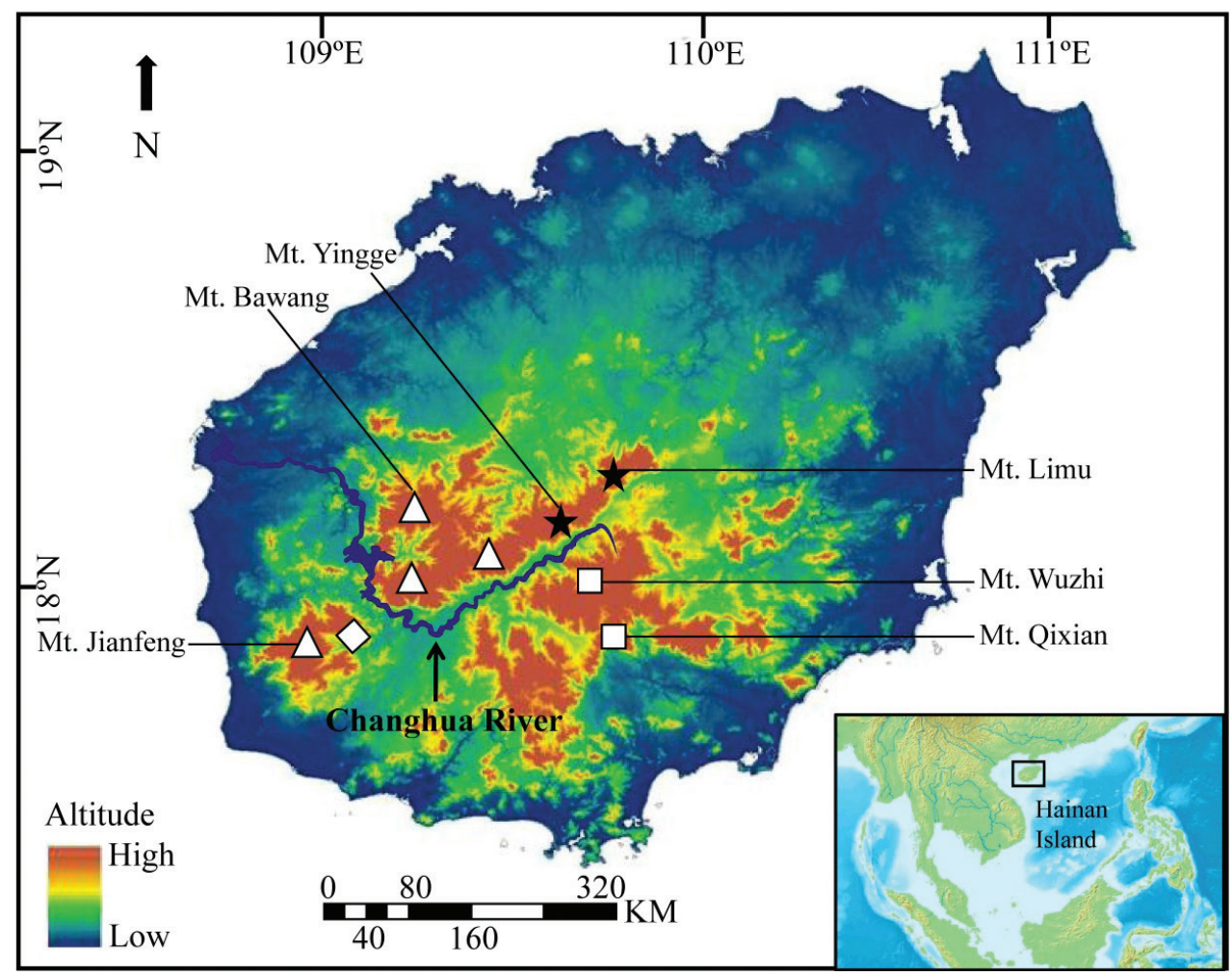

Figure 5. Geographic distribution of Oreocharis jasminina sp. nov. and the three congeners on Hainan Island. $\star$ O. jasminina sp. nov. $\triangle O$. dasyantha $\diamond O$. dasyantha var. ferruginosa $\square O$. flavida.

shape has a strong connection with the expected pollinators in Gesneriaceae, for example, bees or hummingbirds for tubular flowers, bats for campanulate flowers and subcampanulate flowers having generalised pollination systems (Martén-Rodríguez et al. 2009). O. jasminina has thin-tubular corolla (Fig. 1), differing from $O$. dasyantha, $O$. dasyantha var. ferruginosa (both are conical corolla) and O. flavida (campanulatetubular corolla), indicating a possible pollination mechanism associated with the longtongued butterflies and moths. Such distinctive morphological differences indicate different pollination adaptation and clear reproductive isolation amongst these taxa, suggesting $O$. jasminina should be treated as a new species.

\section{Acknowledgements}

This work was funded by the Innovative Team Program of Hainan Natural Science Foundation (2018CXTD331, 2018CXTD334), National Natural Science Foundation of China (41871041) and the Postgraduate Innovation Project of Biological Science of Hainan University. 


\section{References}

Castellanos MC, Wilson P, Thomson JD (2004) 'Anti-bee' and 'pro-bird' changes during the evolution of hummingbird pollination in Penstemon flowers. Journal of Evolutionary Biology 17(4):876-885. https://doi.org/10.1111/j.1420-9101.2004.00729.x

Chen WH, Shui YM, Yang JB, Wang H, Nishii K, Wen F, Zhang ZR, Möller M (2014) Taxonomic status, phylogenetic affinities and genetic diversity of a presumed extinct genus, Paraisometrum W.T. Wang (Gesneriaceae) from the Karst Regions of Southwest China. PLoS ONE 9(9): e107967. https://doi.org/10.1371/journal.pone.0107967

Doyle JJ, Doyle JL (1987) A rapid DNA isolation procedure for small quantities of fresh leaf tissue. Phytochemical Bulletin19(1): 11-15.

Francisco-Ortega J, Wang ZS, Wang FG, Xing FW, Liu H, Xu H, Xu WX, Luo YB, Song XQ, Gale S, Boufford DE, Maunder M, An SQ (2010) Seed plant endemism on Hainan Island: A framework for conservation actions. Botanical Review 76(3): 346-376. https:// doi.org/10.1007/s12229-010-9055-7

Hall TA (1999) BioEdit: A user-friendly biological sequence alignment editor and analysis program for Windows 95/98/NT. Nucleic Acids Symposium Series41: 95-98.

Huelsenbeck JP, Ronquist F (2001) MRBAYES: Bayesian inference of phylogenetic trees. Bioinformatics (Oxford, England) 17(8): 754-755. https://doi.org/10.1093/bioinformatics/17.8.754

IUCN (2012) IUCN Red List Categories and Criteria, Version 3.1 (2 $2^{\text {nd }}$ edition). IUCN Species Survival Commission, Gland \& Cambridge. https://www.iucnredlist.org/technical-documents/categories-and-criteria

Kumar S, Ne iM, Dudley J, Tamura K (2008) MEGA: a biologist-centric software for evolutionary analysis of DNA and protein sequences. Briefings in Bioinformatics 9(4): 299306. https://doi.org/10.1093/bib/bbn017

Li ZY, Wang YZ (2005) Plants of Gesneriaceae in China. Henan Science \& Technology Publishing House, Zhengzhou, 14-67.

Li G, Ling SJ, Chen WF, Ren MX, Tang L (2019) Effects of geographic isolation caused by Changhua River on genetic diversity of Hainan-endemic Metapetrocosmea peltata (Gesneriaceae). Guihaia.

Ling SJ, Meng QW, Tang L, Ren MX (2017a) Gesneriaceae on Hainan Island: distribution patterns and phylogenetic relationships. Biodiversity Sciences 25: 807-815. https://doi. org/10.17520/biods.2016360

Ling SJ, Meng QW, Tang L, Ren MX (2017b) Pollination syndromes of Chinese Gesneriaceae: a comparative study between Hainan Island and neighboring regions. Botanical Review 83: 59-73. https://doi.org/10.1007/s12229-017-9181-6

Ling S-J, Qin X-T, Song X-Q, Zhang L-N, Ren M-X (2020) Genetic delimitation of Oreocharis species from Hainan Island. In: Shui Y-M, Chen W-H, Ren M-X, Wen F, Hong X, Qiu Z-J, Wei Y-G, Kang M (Eds) Taxonomy of Gesneriaceae in China and Vietnam. PhytoKeys 157: 59-81. https://doi.org/10.3897/phytokeys.157.32427

Martén-Rodríguez S, Almarales-Castro A, Fenster CB (2009) Evaluation of pollination syndromes in Antillean Gesneriaceae: Evidence for bat, hummingbird and generalized flowers. Journal of Ecology 97(2): 348-359. https://doi.org/10.1111/j.1365-2745.2008.01465.x 
Möller M (2019) Species discovery in time: An example from Gesneriaceae in China. Guangxi Sciences 26(1): 1-16.

Möller M, Clark L (2013) The state of molecular studies in the family Gesneriaceae: A review. Selbyana 31: 95-125.

Möller M, Middleton D, Nishii K, Wei YG, Sontag S, Weber A (2011) A new delineation for Oreocharis incorporating an additional ten genera of Chinese Gesneriaceae. Phytotaxa 23(1): 1-36. https://doi.org/10.11646/phytotaxa.23.1.1

Möller M, Wei YG, Wen F, Clark JL, Weber A (2016) You win some, you lose some: Updated generic delineations and classification of Gesneriaceae-implications for the family in China. Guihaia 36(1): 44-60.

Möller M, Atkins HJ, Bramley GLC, Middleton DJ, Baines R, Nguyen VD, Bui HQ, Barber S (2018) Two new species of Oreocharis (Gesneriaceae) from Northern Vietnam. Edinburgh Journal of Botany 75(3): 309-319. https://doi.org/10.1017/S0960428618000148

Muchhala N (2007) Adaptive trade-off in floral morphology mediates specialization for flowers pollinated by bats and hummingbirds. American Naturalist 169: 494-504. https://doi. org/10.1086/512047

Pan KY (1987) Taxonomy of the genus Oreocharis (Gesneriaceae). Journal of Systematics and Evolution 25(4): 264-293. http://www.jse.ac.cn/CN/Y1987/V25/I4/264

Robin VV, Vishnudas CK, Gupta P, Ramakrishnan U (2015) Deep and wide valleys drive nested phylogeographic patterns across a montane bird community. Proceedings of the Royal Society B: Biological Sciences 282: 20150861. https://doi.org/10.1098/rspb.2015.0861

Sargent RD (2004) Floral symmetry affects speciation rates in angiosperms. Proceedings of the Royal Society B: Biological Sciences 271(1539): 603-608. https://doi.org/10.1098/rspb.2003.2644 Shen ZH, Yang MZ, Feng JM, Li XH, Peng PH, Zheng Z (2017) Geographic patterns of alpine flora in China in relation to environmental and spatial factors. Biodiversity Sciences 25(2): 182-194. https://doi.org/10.17520/biods.2017014

Swofford DL (2003) PAUP*: Phylogenetic analysis using parsimony (* and other methods) Version 4.0b10. Sinauer Associates, Sunderland, Massachusetts.

Taberlet P, Gielly L, Pautou G, Bouvet J (1991) Universal primers for amplification of three non-coding regions of chloroplast DNA. Plant Molecular Biology 17(5): 1105-1109. https://doi.org/10.1007/BF00037152

Wei YG (2010) Gesneriaceae of South China. Guangxi Science and Technology Publishing House, Nanning, 20-52.

Wen F, Li S, Xin ZB, Fu LF, Hong X, Cai L, Qin JQ, Pan B, Pan FZ, Wei YG (2019) The updated plant list of Gesneriaceae in China under the new Chinese naming rules. Guangxi Sciences 26(1): 37-63.

White TJ, Bruns TD, Lee SB, Taylor J (1990) Amplification and direct sequencing of fungal ribosomal RNA genes for phylogenetics. PCR Protocols 1990: 315-322. https://doi. org/10.1016/B978-0-12-372180-8.50042-1

Xing EN, Xu ST, Ren MX (2018) Age structure and gene flows of fine-scale populations of Oreocharis dasyantha (Gesneriaceae), an alpine herb endemic to Hainan Island. Journal of Tropical Biology 9(1): 37-46.

Xu WB, Guo J, Pan B, Zhang Q, Liu Y (2017) Diversity and distribution of Gesneriaceae in China. Guihaia 37(10): 1219-1226. 


\section{Appendix I}

The Oreocharis specimens we checked in this study.

\begin{tabular}{|c|c|c|c|}
\hline Voucher Number & Species & Voucher Number & Species \\
\hline PE00030859 & Oreocharis rhytidophylla & bm000041491 & Oreocharis aurantiaca \\
\hline IBSC0004917 & Oreocharis henryana & gh00353683 & Oreocharis dentata \\
\hline A00353713 & Oreocharis magnidens & $\mathrm{k} 000858130$ & Oreocharis maximowiczii \\
\hline bm000041734 & Oreocharis benthamii & e00087519 & Oreocharis tubicella \\
\hline $\mathrm{e} 00067455$ & Oreocharis cavaleriei & $\mathrm{e} 00087520$ & Oreocharis nemoralis \\
\hline $\mathrm{a} 00025113$ & Oreocharis flavida & IBSC0004912 & Oreocharis aurea \\
\hline bm000041721 & Oreocharis georgei & p04060117 & Oreocharis forrestii \\
\hline KUN1219176 & Oreocharis cordato-ovata & e00135096 & Oreocharis amabilis \\
\hline e00087535 & Oreocharis dasyantha & $\mathrm{e} 00135074$ & Oreocharis bodinieri \\
\hline bm000041708 & Oreocharis cinnamomea & gh00353695 & $\begin{array}{l}\text { Oreocharis benthamii var. } \\
\text { reticulata }\end{array}$ \\
\hline PE00030854 & Oreocharis tubiflora & p04060171 & Oreocharis delavayi \\
\hline IBSC0004920 & Oreocharis xiangguiensis & CSFI028502 & Oreocharis brachypodus \\
\hline PE19401111 & Oreocharis amabilis & PE02052999 & Oreocharis heterandra \\
\hline IBSC0550960 & Oreocharis sericea & IBSC0550860 & Oreocharis cordatula \\
\hline IBSC0550891 & Oreocharis georgei & IBSC0550875 & Oreocharis elliptica \\
\hline GZTM0075588 & Oreocharis primuloides & JIU63907 & Oreocharis speciosa \\
\hline PE02052990 & Oreocharis argyreia var. angustifolia & PE02053568 & Oreocharis eximia \\
\hline IBK00054784 & Oreocabris auricula & PE01909883 & Oreocharis mileensis \\
\hline KUN1219104 & Oreocharis hekouensis & WUK0494363 & Oreocharis saxatilis \\
\hline PE02053062 & Oreocharis concava & PE01486523 & Oreocharis rosthornii \\
\hline PE02106072 & Oreocharis begoniifolia & KUN1385365 & Oreocharis nanchuanica \\
\hline KUN1385575 & Oreocharis urceolata & HITBC106680 & Oreocharis longifolia \\
\hline PE00030861 & Oreocharis rotundifolia & IBSC0548683 & Oreocharis chienii \\
\hline PE02053433 & Oreocharis acaulis & KUN1385156 & Oreocharis bullata \\
\hline PE02241281 & Oreocharis burttii & PE02053072 & Oreocharis cinerea \\
\hline KUN1220227 & Oreocharis convexa & IBK00054466 & Oreocharis cotinifolia \\
\hline PE00155697 & Oreocharis craibii & WUK0350789 & Oreocharis crenata \\
\hline IBSC0550709 & Oreocharis dalzielii & PE02106079 & Oreocharis dinghushanensis \\
\hline IBSC0551649 & Oreocharis esquirolii & PE02052984 & Oreocharis fargesii \\
\hline IBSC0649611 & Oreocharis flabellata & PE02053533 & Oreocharis gamosepala \\
\hline PE02052812 & Oreocharis giraldii & PE02106025 & Oreocharis glandulosa \\
\hline PE02052995 & Oreocharis humilis & PE01548041 & Oreocharis jiangxiensis \\
\hline PE02021009 & Oreocharis lancifolia & FJSI004239 & Oreocharis leiophylla \\
\hline PE02053066 & Oreocharis leucantha & IBSC0550069 & Oreocharis lungshengensis \\
\hline IBSC0551655 & Oreocharis mairei & PE02053564 & Oreocharis minor \\
\hline WUK0160594 & Oreocharis muscicola & IBSC0548476 & Oreocharis notochlaena \\
\hline PE02106041 & Oreocharis obliqua & PE02052801 & Oreocharis obliquifolia \\
\hline PE02088092 & Oreocharis obtusidentata & PE02053064 & Oreocharis pankaiyuae \\
\hline PE01270485 & Oreocharis primuloides & WUK0213194 & Oreocharis pumila \\
\hline PE02053576 & Oreocharis pinnatilobata & KUN1241303 & Oreocharis primuliflora \\
\hline PE02053532 & Oreocharis rhombifolia & PE00030693 & Oreocharis ronganensis \\
\hline PE00030747 & Oreocharis sichuanensis & IBSC0550081 & Oreocharis sichuanica \\
\hline IBK00054319 & Oreocharis sinensis & IBK00207093 & Oreocharis sinohenryi \\
\hline PE02053579 & Oreocharis stenosiphon & IBSC0548730 & Oreocharis stewardii \\
\hline PE02053570 & Oreocharis trichantha & HEAC0016525 & Oreocharis villosa \\
\hline PE02053561 & Oreocharis wangwentsaii & PE02053077 & Oreocharis wanshanensis \\
\hline $\begin{array}{l}\text { Y. M. Shui et al. } \\
\text { B2014-299 (KUN) }\end{array}$ & Oreocharis synergia & $\begin{array}{l}\text { Y.M.Shui et al. N699 } \\
\text { (KUN) }\end{array}$ & Oreocharis ninglangensis \\
\hline
\end{tabular}




\begin{tabular}{|c|c|c|c|}
\hline Voucher Number & Species & Voucher Number & Species \\
\hline PE-02114626 & Oreocharis duyunensis & IBSC0825078 & Oreocahris ovata \\
\hline KUN1219115 & Oreocharis acutiloba & PE00030682 & Oreocharis agnesiae \\
\hline PE00140281 & Oreocharis billburttii & PE02025205 & Oreocharis elegantissima \\
\hline IBSC0649550 & Oreocharis latisepala & PE00030685 & Oreocharis parva \\
\hline $\begin{array}{l}\text { Z.K. Wu et } \\
\text { al.C2016055 } \\
\text { (KUN) }\end{array}$ & Oreocharis parvifolia & PE02025202 & Oreocharis pinfaensis \\
\hline IBSC0548691 & Oreocharis shweliensis & PE01909893 & Oreocharis tongtchouanensis \\
\hline $\begin{array}{l}\text { Y.M.Shui, Y.K.Sima } \\
\text { \& W.H.Chen } \\
\text { B2013-258 (KUN) }\end{array}$ & Oreocharis crispata & $\begin{array}{l}\text { Y.M.Shui et al. } 91309 \\
\text { (KUN) }\end{array}$ & Oreocharis jinpingensis \\
\hline $\begin{array}{l}\text { Bo Pan \& M. Q. } \\
\text { Han HMQ859 } \\
\text { (IBK) }\end{array}$ & Oreocharis purpurata & $\begin{array}{l}\text { Yun-Hong Tan } 3308 \\
\text { (HITBC) }\end{array}$ & Oreocharis tsaii \\
\hline $\begin{array}{l}\text { Averyanov, L., Hiep, } \\
\text { N.T., Khang, N.S., } \\
\text { Thang, N.D. \& Qui, } \\
\text { L.D. CPC } 7019 \\
\text { (KUN) }\end{array}$ & Oreocharis blepharophylla & $\begin{array}{l}\text { Jia-Mei Li and } \\
\text { Yao-Guang Zhang } \\
1606151 \text { (HEAC) }\end{array}$ & Oreocharis zhenpingensis \\
\hline $\begin{array}{l}\text { Bo Pan \& Jia-Jia Wei } \\
\text { et al. GY002 (IBK) }\end{array}$ & Oreocharis curvituba & $\begin{array}{l}\text { C.Z. Yang et al. } \\
35042620140913001 \\
\text { (FNU) }\end{array}$ & Oreocharis striata \\
\hline $\begin{array}{l}\text { Y.M. Shui et al. } \\
\text { B2013-551 (KUN) }\end{array}$ & Oreocharis longituba & $\begin{array}{l}\text { Averyanov, L., Hiep, } \\
\text { N.T., Khang, N.S., } \\
\text { Thang, N.D. \& Qui, } \\
\text { L.D. CPC } 7175 \\
\text { (KUN) }\end{array}$ & Oreocharis argyrophylla \\
\hline $\begin{array}{l}\text { Y.M. Shui et al. } \\
\text { B2013-550 }\end{array}$ & Oreocharis grandiflora & T.V. Do 57 (VNMN) & Oreocharis caobangensis \\
\hline $\begin{array}{l}\text { L.H. Yang et al. } \\
\text { YLH197 (IBSC) }\end{array}$ & Oreocharis pilosopetiolata & $\begin{array}{l}\text { Li-Hua Yang et al. } \\
\text { YLH285 (IBSC) }\end{array}$ & Oreocharis uniflora \\
\hline $\begin{array}{l}\text { Ying Guo } \\
\text { C2015005 (KUN) }\end{array}$ & Oreocharis panzhouensis & L. E. Yang 60 (KUN) & Oreocharis rubrostriata \\
\hline $\begin{array}{l}\text { Yan Liu and Wei-Bin } \\
\text { Xu } 08018 \text { (IBK) }\end{array}$ & Oreocharis dayaoshanioides & $\begin{array}{l}\text { Yun-Hong Tan } 6925 \\
\text { (HITBC) }\end{array}$ & Oreocharis glandulosa \\
\hline PE 02053063 & Oreocharis farreri & $\begin{array}{l}\text { Lin Qin-Wen et al. } \\
0016 \text { (FAFU) }\end{array}$ & Oreocharis baolianis \\
\hline IBSC0548624 & Oreocharis guileana & IBK00054993 & $\begin{array}{l}\text { Oreocharis dasyantha var. } \\
\text { ferruginosa }\end{array}$ \\
\hline
\end{tabular}

